\title{
Understanding snow-transport processes shaping the mountain
}

\section{snow-cover}

\author{
R. Mott, M. Schirmer, M. Bavay, T. Grünewald, and M. Lehning \\ WSL Institute for Snow and Avalanche Research SLF, 7260 Davos Dorf, Switzerland
}

Received: 15 June 2010 - Published in The Cryosphere Discuss.: 7 July 2010

Revised: 11 November 2010 - Accepted: 16 November 2010 - Published: 2 December 2010

\begin{abstract}
Mountain snow-cover is normally heterogeneously distributed due to wind and precipitation interacting with the snow cover on various scales. The aim of this study was to investigate snow deposition and wind-induced snow-transport processes on different scales and to analyze some major drift events caused by north-west storms during two consecutive accumulation periods. In particular, we distinguish between the individual processes that cause specific drifts using a physically based model approach. Very high resolution wind fields $(5 \mathrm{~m})$ were computed with the atmospheric model Advanced Regional Prediction System (ARPS) and used as input for a model of snow-surface processes (Alpine3D) to calculate saltation, suspension and preferential deposition of precipitation. Several flow features during north-west storms were identified with input from a high-density network of permanent and mobile weather stations and indirect estimations of wind directions from snowsurface structures, such as snow dunes and sastrugis. We also used Terrestrial and Airborne Laser Scanning measurements to investigate snow-deposition patterns and to validate the model. The model results suggest that the in-slope deposition patterns, particularly two huge cross-slope cornicelike drifts, developed only when the prevailing wind direction was northwesterly and were formed mainly due to snow redistribution processes (saltation-driven). In contrast, more homogeneous deposition patterns on a ridge scale were formed during the same periods mainly due to preferential deposition of precipitation. The numerical analysis showed that snow-transport processes were sensitive to the changing topography due to the smoothing effect of the snow cover.
\end{abstract}

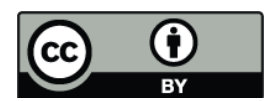

Correspondence to: R. Mott (mott@slf.ch)

\section{Introduction}

Snow-transport processes shape the mountain snow-cover during the winter season. The driving force for these processes is the atmospheric boundary layer flow. The mean air flow is modified by the local topography, especially in highly complex terrain. Local high wind velocities initiate the relocation of snow particles already deposited on the ground, through saltation and suspension processes. Additionally, the interaction of wind and topography during snowfall promotes enhanced snow loading on leeward slopes due to the preferential deposition of the precipitation (Lehning et al., 2008). These process interactions result in very heterogeneous snow depths and snow-cover properties. The heterogeneity of snow-cover properties arising from particular storm events, on the one hand, is a special challenge for avalanche forecasting (e.g. Schweizer et al., 2003). The snow distribution at the time of peak accumulation, on the other hand, has a major influence on the timing and the magnitude of snowmelt runoff (Pomeroy et al., 1997; Luce et al., 1998; Liston et al., 2007; Grünewald et al., 2010).

There have been several attempts to provide physically based descriptions of saltation and suspension, which are the main mechanisms for snow transport by wind (Mellor, 1965; Male, 1980; Schmidt, 1986; Pomeroy and Gray, 1990; Lehning and Fierz, 2008). In recent years, more complex model approaches have been developed which use high-resolution atmospheric three-dimensional wind fields (Raderschall et al., 2008) to drive the snow-drift models (Gauer, 2001; Liston and Elder, 2006; Lehning et al., 2008). Lehning et al. (2008) introduced the process of preferential deposition of precipitation as an additional mechanism, that influences the distribution when solid precipitation is transported by wind.

Wind flow patterns and their related snow-drift processes are highly complex. Moreover, computational costs are high. This is why most attempts to model snow transport by wind

Published by Copernicus Publications on behalf of the European Geosciences Union. 
have relied on simplification, either using simple terrainbased parameters on snow distribution (Purves et al., 1998; Winstral and Marks, 2002; Winstral et al., 2002) or empirical and analytical relationships between topographical parameters, wind velocity and transport rates of snow (Tabler, 1975; Uematsu et al., 1991; Liston et al., 2007). It has been suggested, however, that the driving wind field is the most sensitive parameter for simulating the small-scale distribution of snow (Lehning et al., 2000; Essery, 2001; Raderschall et al., 2008; Dadic et al., 2010a). Thus, an adequate representation of the characteristic flow features for Alpine terrain, such as crest separation and flow blocking, is essential for snowdrift modeling on very small scales (tens of meters). Previously, atmospheric mean flow fields have been successfully used to model snow drifts in very complex terrain (Bernhardt et al., 2010; Mott and Lehning, 2010). When atmospheric models were applied to glaciated terrain, it was found that a horizontal grid resolution of $25 \mathrm{~m}$ is sufficient to represent ridge-scale deposition features (Mott et al., 2008; Dadic et al., 2010a). There seems to be a strong negative correlation between the main seasonal accumulation areas on Alpine glaciers and increased horizontal and decreased downward surface-normal wind velocities. However, a recent investigation on snow-transport processes suggests that the spatial resolution used in the related numerical analysis is still insufficient to capture the snow-deposition features caused by pure drift processes (Mott and Lehning, 2010). A more realistic representation of the small-scale deposition patterns, such as dunes and cornices, is very sensitive to grid resolution and can only be achieved if a horizontal resolution of $10 \mathrm{~m}$ or less is used.

To our knowledge, beside the studies of Gauer (2001), Fang and Pomeroy (2009) and Mott and Lehning (2010) all previous studies on snow-drift modeling have used horizontal grid resolutions of $25 \mathrm{~m}$ or coarser. Furthermore, most of the studies performed in Alpine catchments to date have used low-density spatial and temporal measurements of snow depths and meteorological data (e.g. Bernhardt et al., 2010), which makes their promising results difficult to validate. Combining high-resolution measurements of the snow cover using airborne and terrestrial laser scanning with a dense network of meteorological stations provides a way to examine the spatial and temporal development of the snow cover (Schirmer et al., 2010b), as well as the driving atmospheric forces for drifting and blowing snow on a very small scale of just a few meters. These measurements also ensure that the validation of atmospheric and snow-transport models is adequate and help to analyze different snow-transport processes.

In this paper, we address four main points concerning the understanding of snow-transport processes shaping the snow cover on a high-alpine wind-blown landscape. First, we discuss and show observed and modeled flow patterns. Second, we discuss the spatial pattern of deposited and redistributed snow after several snowfall and storm events based
Table 1. Instrumentation: measured variables (Variable) (wind velocity (vw), air temperature (ta), relative humidity (RH), snow surface temperature (tss), snow depth (hs), incoming longwave radiation (LWRin), outgoing longwave radiation (LWRout), incoming shortwave radiation (SWRin), incoming shortwave radiation (SWRout), solar radiation (rad)); type of sensors (Sensors) and number of stations equipped with sensors $(\sharp)$.

\begin{tabular}{lll}
\hline Variable & Sensor & $\sharp$ \\
\hline \multicolumn{2}{c}{ 7 Permanent Stations } \\
\hline vw & uvw anemometer & 4 \\
vw & Young & 3 \\
ta & MP100H/T107 & 7 \\
RH & Hygroclip S3 & 7 \\
tss & IR & 4 \\
hs & SR 50 & 6 \\
LWRin/out & CNR1 & 4 \\
SWRin/out & CNR1 & 4 \\
\hline & 17 SensorScope Stations & \\
\hline \multirow{2}{*}{ vw } & Davis Anemometer & 17 \\
ta, RH & SHT75, Sensirion & 17 \\
tss & TN901, Zytemp & 7 \\
rad & Davis solar Radiation & 9 \\
\hline
\end{tabular}

on high resolution measurements and a physical-based model description. Third, we investigate the influence of the changing topography during the accumulation period on the development of drifts observed in the investigation area. Finally, we identify the spatial characteristics of deposition patterns using statistics and relate them to the main snow-transport mechanisms and their dominance in specific areas as controlled by the local flow field.

\section{Methods}

\subsection{Site description, measurements and analysis strategy}

Our study site, the Wannengrat area is near the town of Davos, Switzerland and has been successfully established as an investigation area for snow-cover and snowhydrology related studies (Grünewald et al., 2010; Bellaire and Schweizer, 2010; Schirmer et al., 2010b). The whole area is located above the local tree-line at altitudes ranging from $2000 \mathrm{~m}$ to $2658 \mathrm{~m}$ a.s.l. (Fig. 1). The investigation area is equipped with seven permanent weather stations (WAN 17) and an additional 17 mobile stations (SensorScope, Swiss Experiment; available at: http://www.swiss-experiment.ch), shown in Fig. 1. The SensorScope stations were concentrated around the Wannengrat pyramid, the Latschüelfurgga and on a leeward slope, which we refer to as the Bowl. All meteorological stations were equipped with wind sensors (Table 1). For our study site the accumulation period 2008/09 lasted 


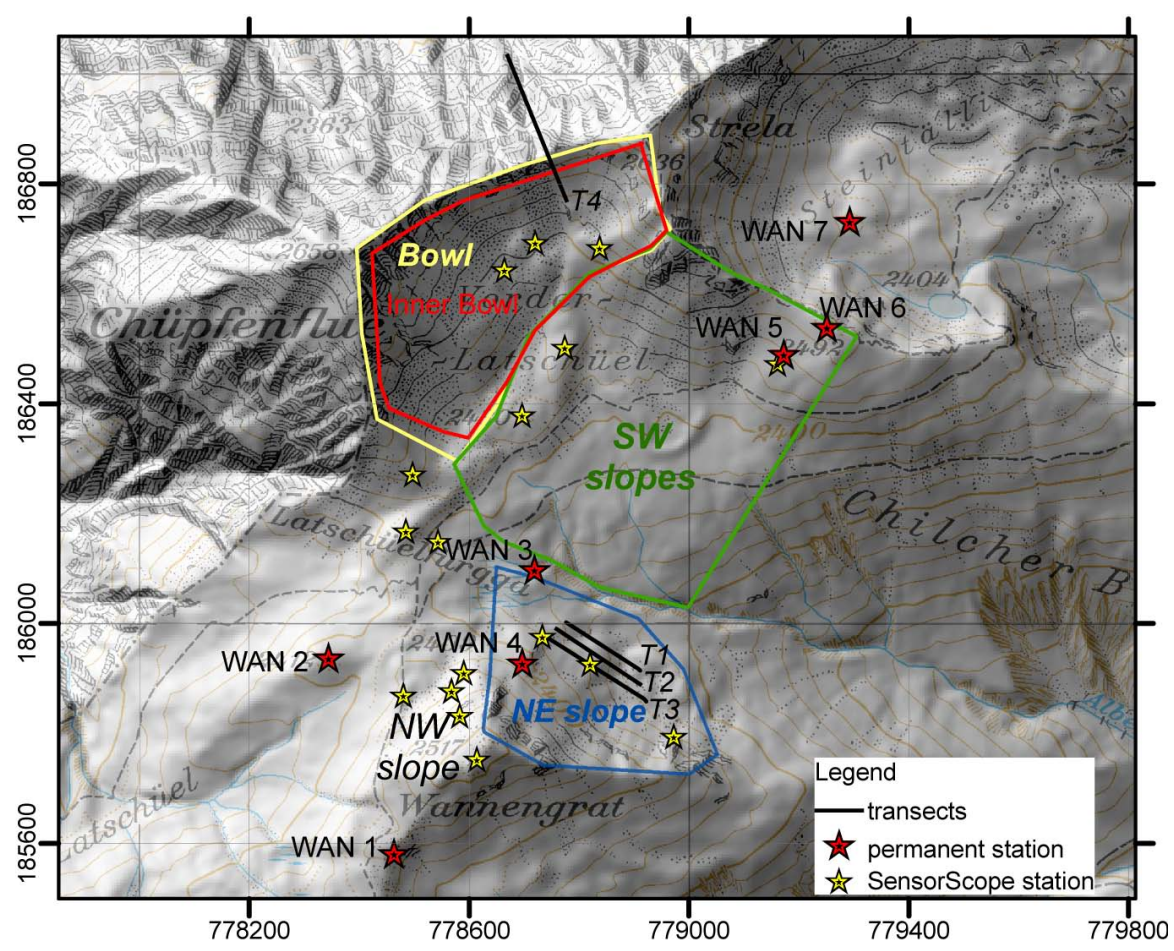

Fig. 1. Location of the study site in the Wannengrat area near Davos. The $\mathrm{x}$ and y-axes indicate Swiss coordinates in meters. Colored lines enclose the four sub-areas investigated. SensorScope stations are marked with yellow stars and permanent weather stations (WAN 1-7) are marked with red stars. The four black lines (numbered from T1 to T4) mark the transects shown in Figs. 5, 8, 10, 11 and Table 2. (basemap: Pixelkarte PK 25 @2009 swisstopo (dv033492)).

from 27 October 2008 until 9 April 2009 (time of peak accumulation), whereas the accumulation period 2009/10 started on the 12 October 2009 and ended on 19 April 2010 (time of peak accumulation). Complete melt of seasonal snow is usually observed in June. At the SLF flat field research site Versuchsfeld Weissfluhjoch a total snow-water (HNWsum) of $807 \mathrm{~mm}$ was measured for winter 2008/09 and $613 \mathrm{~mm}$ for winter 2009/10. During the two accumulation periods the air temperature ranged from $-24^{\circ} \mathrm{C}$ to $+10^{\circ} \mathrm{C}$.

To gain additional information about the local flow direction, we used snow-surface structures, such as snow drifts and sastrugis, as proxy data for wind direction. We expected these structures to allow the locally dominant flow directions to be adequately identified and thus provide further verification for numerical wind field simulations for specific areas. The appearance of surface structures could also be used to distinguish areas of low and high wind velocities. These proxy data from the snow surface were based on orthophotos with a pixel resolution between 7 and $9 \mathrm{~cm}$, obtained from the Terrestrial Laser Scanner (TLS) surveys. We chose orthophotos obtained from the first measurement campaign for one typical event in October 2009 since sastrugis were well developed after this snowfall event. Wind data during northwest (NW) storms tend to be very consistent (see Sect. 3.1.), which meant we could assume that these surface structures would be representative for all NW storms.
Snow depths were measured with a Terrestrial Laser Scanner (Riegl LPM-321) before and after several drift events in winter 2008/2009 and winter 2009/2010 (Fig. 2). Additionally, the snow depth distribution was measured at the time of peak accumulation for the winters 2007/08, 2008/09 and 2009/10. A detailed description of the measurement set-up and error estimation of the TLS in the Wannengrat area can be found in Grünewald et al. (2010). For more general discussions of the application of laser-scanning technology to snow depth measurements, see Prokop (2008), Prokop et al. (2008) and Schaffhauser et al. (2008). The final raster maps of snow depth (HS) and snow depth change (dHS) due to individual snow-drift events have a cell size of $1 \mathrm{~m}$ for each survey. To cover a larger area without measurement gaps, the snow depths at the time of peak accumulation were also measured using Airborne Laser Scanning (ALS) at the end of the accumulation periods of 2007/2008 and 2008/2009. For these two campaigns a helicopter based technology (Skaloud et al., 2006) was used. Grünewald et al. (2010) studied both methods and found a mean error of HS in the order of centimeters. The series of TLS measurements in the Wannengrat area revealed a very strong inter-annual consistency between the snow depths at time of peak accumulation of the winters 2007/2008 and 2008/2009 (Schirmer et al., 2010b). The correlations between snow depths at these two dates were $r=0.97$ on the NE slope and $r=0.93$ in the Bowl. The 

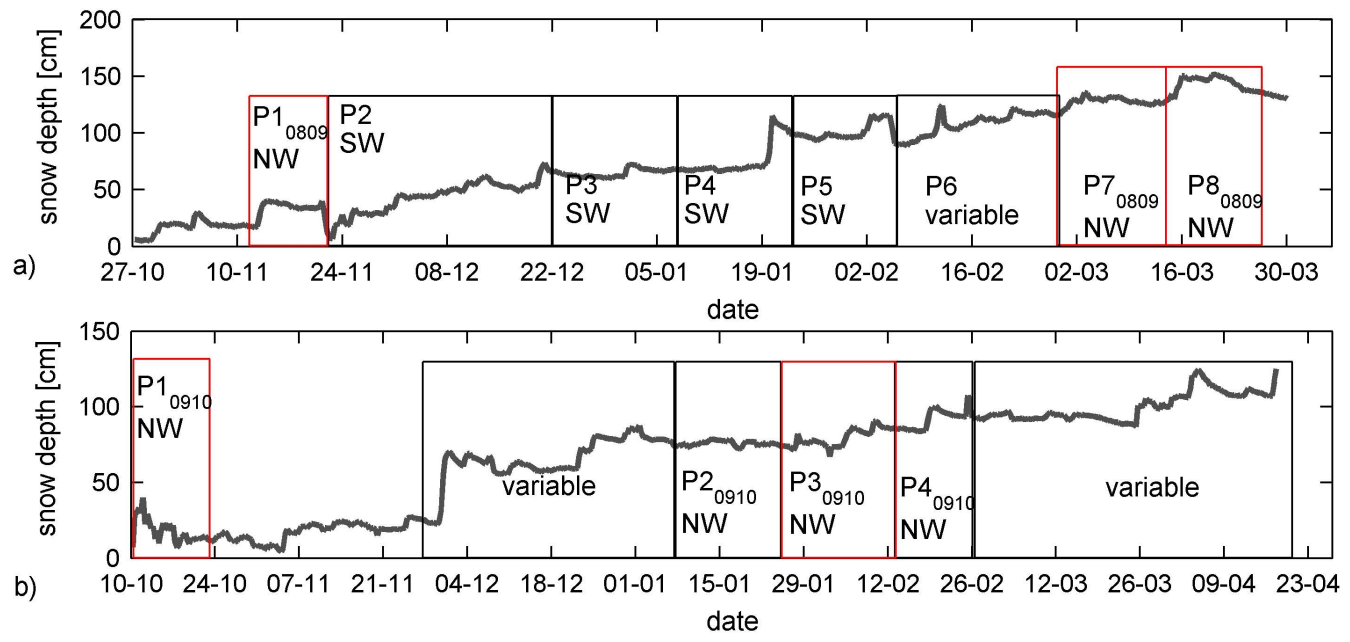

Fig. 2. Time series of snow-depth development during the accumulation seasons 2008/09 (a) and 2009/10 (b) at WAN 7. Snow-drift events are marked with boxes. Measured snow-drift events are additionally marked with $\mathrm{P}$, and those events referred to in the paper are drawn in red.

NW storms correlated strongly with measured HS on the NE slope at the time of peak accumulation, with $r=0.88$ for the first NW storm $\left(\mathrm{P}_{0809}\right)$ of the winter 2008/09 and $r=0.76$ for the last NW storm of this winter $\left(\mathrm{P}_{0809}\right)$. The snow deposition patterns found after NW storms were very similar and contributed significantly to the final snow depth distribution at the time of peak accumulation. We therefore only focused on those drift events caused by NW storms (Fig. 2). To examine these typical events, we selected three drift events in 2008/2009 and two drift events in 2009/2010 affected by NW storms.

\subsection{Model set-up for flow field and drift simulations}

We calculated the mean flow fields with the non-hydrostatic and compressible atmospheric model Advanced Regional Prediction System (ARPS), developed at the Center for Analysis and Prediction of Storms (CAPS), University of Oklahoma (Xue et al., 2004). We were only interested in the mean wind fields because measurements showed very consistent mean hourly wind directions during NW storms (Fig. 3). Therefore we assume that these mean wind fields may explain observed deposition patterns consistent with earlier results (Raderschall et al., 2008; Dadic et al., 2010a; Mott and Lehning, 2010).

The ARPS model was initialized using horizontally homogeneous fields and artificial vertical profiles of the atmosphere, which described the atmosphere for a characteristic situation during snowfall. The atmosphere was assumed to be slightly stably stratified and nearly saturated. We used a standard logarithmic profile of the horizontal wind within the boundary layer and defined a vertically constant freestream velocity above the boundary layer. The height of the boundary layer was set to $500 \mathrm{~m}$. For all model runs, a snow-

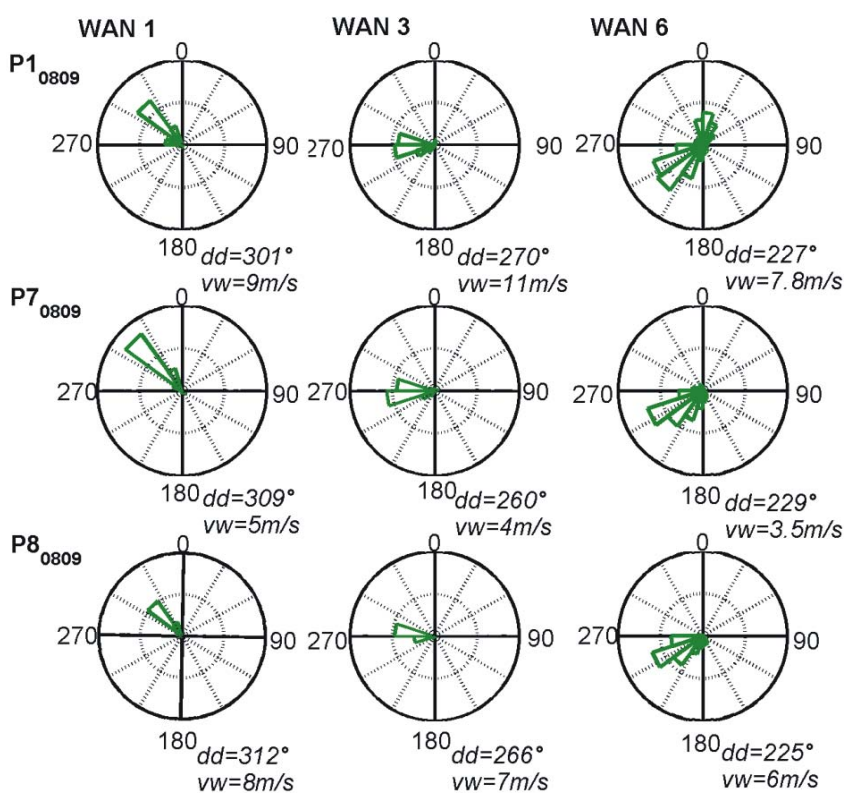

Fig. 3. Wind roses for the permanent weather stations WAN 1, WAN 3 and WAN 6 for the three NW storms $\mathrm{P} 1_{0809}, \mathrm{P}_{0809}$ and $\mathrm{P} 8$ 0809. dd stands for the mean wind direction and $\mathrm{vw}$ for the mean wind velocity of the entire periods.

covered topography was taken into consideration by using an aerodynamic roughness length of $z_{0}=0.01 \mathrm{~m}$, which is in agreement with measurements by Doorschot et al. (2004) and Stössel et al. (2010) in similar terrain. We used a zerogradient formulation for the upper boundary. For the lateral boundaries periodic boundary conditions were used, which facilitated the conservation of mass within the model domain.

To compute mean flow features, we ran the model for a rather short integration time of $30 \mathrm{~s}$, with the effect that the 
flow could not develop turbulent structures. This was desired for the current application in which only mean flow features as caused by the terrain should be reproduced and had the further side-effect that the model remained stable. The influence of the integration time and boundary conditions on flow adaptation is discussed in detail in Raderschall et al. (2008). The domain covered the surrounding topography of the Wannengrat area, which is considered to have a major influence on the flow field within the investigation area. The domain size was accordingly set to $2.5 \times 2.8 \mathrm{~km}$. To test the influence of the changing topography, we also performed wind simulations for the snow-covered terrain of 2009. Two digital elevation models, the $\mathrm{DEM}_{\mathrm{b}}$ and the $\mathrm{DEM}_{\mathrm{s}}$, were created by a resample of a high resolution airborne laser scan to a $5 \mathrm{~m}$ grid. The $\mathrm{DEM}_{\mathrm{b}}$ was taken in summer 2009, while the $\mathrm{DEM}_{\mathrm{s}}$ was taken at the time of peak accumulation on 9 April 2009. The ARPS model uses a terrain-following coordinate system. The finest vertical grid resolution of about $0.8 \mathrm{~m}$ (mean value) is found close to the ground. Due to grid stretching the vertical resolution of the first level above ground ranges between $0.5 \mathrm{~m}$ at ridges and $1.1 \mathrm{~m}$ at flatter terrain and topographical depressions.

In total five wind fields were modeled, initiated with wind velocities varying between very low $\left(2 \mathrm{~m} \mathrm{~s}^{-1}\right)$ and very high $\left(9 \mathrm{~m} \mathrm{~s}^{-1}\right)$ at $2400 \mathrm{~m}$ a.s.l. The model output is a threedimensional grid of velocity with $\boldsymbol{x}, \boldsymbol{y}, \boldsymbol{z}$ vectors, which was then used as input for the snow-transport model of Alpine3D (Lehning et al., 2008). In this model, the redistribution of snow is calculated as composed of the pure drift processes, saltation (Clifton and Lehning, 2008) and suspension on the one hand, and preferential deposition of precipitation (Lehning et al., 2008) on the other hand. To distinguish between the different wind-induced snow-transport processes, the model allows the process of preferential deposition of precipitation to be calculated separately from saltation and suspension.

Since this study aims to deal with all processes that cause the spatial and temporal variability of the snow depth, we used a full description of the energy balance at the snow surface as implemented in Alpine3D (Helbig et al., 2009, 2010). The energy balance model and snow-transport model are fully coupled to the snow-cover module SNOWPACK (Lehning and Fierz, 2008). This particular model set-up enabled us to account for the influence of the local energy balance on the snow-cover properties and therefore also on the snow-drift processes. We did not account for sublimation of drifting and blowing snow, which would be necessary to capture the whole snow mass balance during snow-drift events. Nevertheless, a detailed investigation of relative humidity with respect to ice $\left(\mathrm{RH}_{\mathrm{i}}\right)$ showed that during simulated drift events only between 2 and $16 \%$ of the hourly $\mathrm{RH}_{\mathrm{i}}$ was below $95 \%$. We therefore assume sublimation to be insignificant for the drift events selected for this study.

One hour was chosen as a suitable model time step. Apart from the three-dimensional wind fields, we updated
Alpine3D with hourly meteorological data, gained from two permanent meteorological stations (WAN 3, WAN 7) within the investigation area (Fig. 1). We assumed relative humidity to be homogeneously distributed over the domain, while air temperature was distributed over the computational domain with an altitudinal gradient of $-0.65^{\circ} \mathrm{C}$ per $100 \mathrm{~m}$. The state of the homogeneously distributed snow-cover properties at the start of a snowfall event was initialized by vertical profiles of the snow cover, calculated with the one-dimensional SNOWPACK module for a flat field station (WAN 7, Fig. 1) within the study area. The three-dimensional wind fields obtained from ARPS were chosen using a classification scheme based on the frequency distribution of wind velocity at the reference wind station (WAN 2, Fig. 1) for the specific periods.

We used two different topographies, the $\mathrm{DEM}_{\mathrm{b}}$ and $\mathrm{DEM}_{\mathrm{s}}$, for atmospheric simulations. Simulations of the first drift events of the two accumulation periods ( $\mathrm{P} 1_{0809}$ and $\left.\mathrm{P} 1_{0910}\right)$ were driven by flow fields calculated over bare ground $\left(\mathrm{DEM}_{\mathrm{b}}\right)$, while the drift periods at the end of the accumulation season ( $\mathrm{P}_{0809}, \mathrm{P}_{0809}$ and $\left.\mathrm{P} 3_{0910}\right)$ were simulated using flow fields calculated over snow-covered terrain $\left(\mathrm{DEM}_{\mathrm{S}}\right)$.

The spatial variability of the modeled and observed snow depth changes (dHS) is explored using the mean $(\mu)$ and standard deviation $(\sigma)$. To calculate the relative contribution of the redistribution processes (saltation and suspension) versus the preferential deposition of precipitation, we had to perform two different simulation runs for each period. We ran the model either with all wind-induced snow-transport processes $\left(\mathrm{dHS}_{\text {all }}\right)$ or only with preferential deposition of precipitation $\left(\mathrm{dHS}_{\mathrm{prec}}\right)$.

\section{Results and discussion}

\subsection{Flow field}

In Fig. 3 wind roses for three permanent stations for the three NW storms in winter 2008/2009 are shown. We averaged the wind data to $10 \mathrm{~min}$ intervals. The plot impressively demonstrates the clear prevailing wind directions for each station for all three NW storms. This time consistency of the prevailing wind directions during NW is also shown by nearly all other stations located in the Wannengrat area, except those which are situated in flow separation zones. It is worth noting that the wind directions are stable over time, but vary strongly between the stations, from north-west at station WAN 1 to south-west at station WAN 6, as forced by the terrain.

A map of the most frequently measured wind directions at each station for a snowfall event in January 2010 is shown in Fig. 4a. This snowfall event $\mathrm{P}_{0910}$ occurred during a synoptically controlled NW wind situation. The length and the color of the wind vectors represent mean wind velocities for the period of $24 \mathrm{~h}$ during 28 January 2010 . The wind directions obtained from snow-surface structures as 

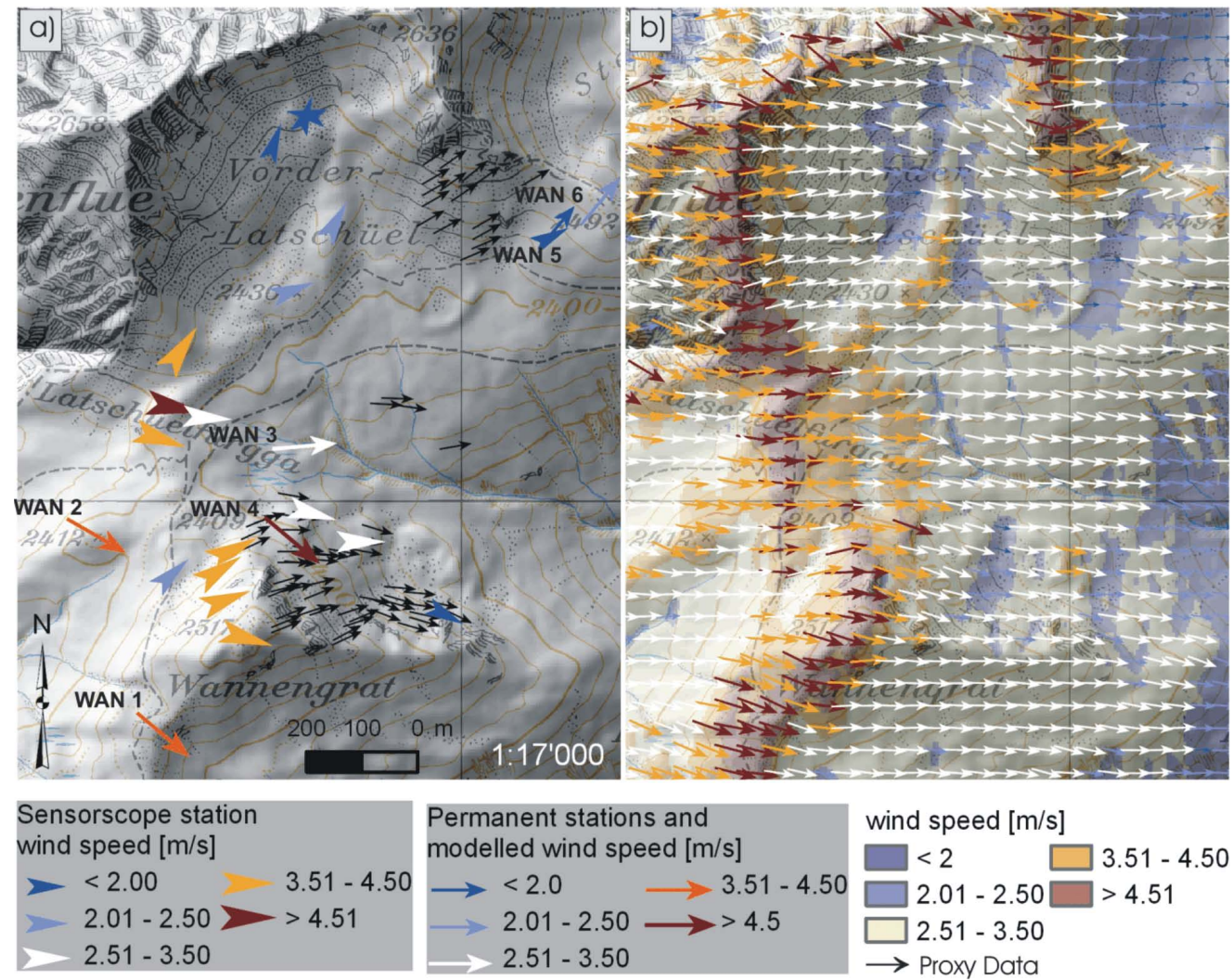

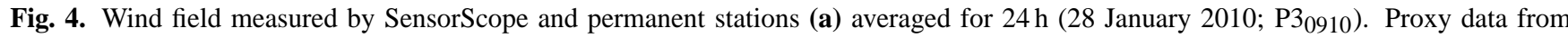
snow-surface structures measured after the snowfall event $\mathrm{P}_{0910}$ are shown by black wind vectors. Modeled wind field for the first level above ground initialized with $2 \mathrm{~m} \mathrm{~s}^{-1}$ at $2400 \mathrm{~m}$ a.s.1. (b). Note that the grid spacing of the model results is $5 \mathrm{~m}$, but only one vector every $30 \mathrm{~m}$ is illustrated. (basemap: Pixelkarte PK 25 (C2009 swisstopo (dv033492)).

described above are indicated with black arrows. The measurements revealed very characteristic flow patterns with a clear influence of the local topography. Despite the time stability of wind directions for the single stations, the local wind patterns varied considerably over small distances of a few hundred meters. On ridges we consistently observed a flow perpendicular to the ridge, similar to what had been observed at Gaudergrat by Lewis et al. (2008). This also includes the flow turning to a southwesterly flow at WAN 5 and WAN 6 and on the slope north of Latschüelfurgga (Fig. 4a). In the lower parts of the NW slope, in contrast, the mobile stations and proxy data displayed evidence of a flow around the Wannengrat pyramid with a southwesterly flow. The main flow on Chilcher Berg and Latschüelfurgga was northwesterly due to channelling (WAN 2, WAN 3). The mobile stations and proxy data on the NE slope showed a clear northwesterly wind direction. Within the Bowl, in contrast, we did not observe such stable wind patterns. Within a small time span of one hour, the flow directions in the windsheltered area vary between southeasterly and southwesterly flows with rather low wind velocities. These varying wind directions and low wind velocities are a clear sign of flow separation on the ridge of Chüpfenflue.
The highest wind velocities were observed on the ridges and on the Latschüelfurgga due to speed-up effects and flow channeling. Increased wind velocities were observed at wind-exposed stations located on bumps and lower wind velocities at those situated in wind-sheltered terrain depressions. Well-developed surface structures, such as sastrugis, due to wind were formed on the NE slope, $N W$ slope and the $S W$ slopes (Fig. 4a), which indicates increased wind velocities in these areas. On the $N E$ slope the surface structures developed more strongly on the windward than on the leeward sides of the two ridges, which indicate high and low wind velocities, respectively. In contrast, no surface structures were formed within the Bowl, which clearly suggested low wind velocities in this area.

In Fig. 4b, the modeled mean flow field for a characteristic NW storm with moderate wind velocities is shown for the first level above ground. A qualitative comparison between the observed mean flow direction and the simulated mean flow direction shows a reasonable agreement for all ridges, with observed flow perpendicular to the ridge. In general, the flow turning to southwest is well presented in the model results, even if the turning to southwest is not as strong as actually shown by the measurements (Fig. 4a). Furthermore, 
the simulations are able to capture the flow around the Wannengrat pyramid. The numerical analysis indicated that this flow is caused by the flow blocking on the lower parts of the $N W$ slope. Sensitivity runs with different atmospheric stabilities (not shown) indicate that this flow blocking presumably developed when there was a slightly stable atmospheric stratification of the atmosphere, mostly found during snow-drift events. The flow around the Wannengrat pyramid is marked by strong speed-up, which may also enhance the flow on the NE slope.

A quantitative evaluation of the modeled wind directions showed that, at locations where the flow was within the westnorthwest sector, the mean deviation between the modeled and the measured mean wind direction was only 6 degrees for all stations. In contrast, the mean deviation at locations where the flow turned to southwest was 17 degrees. Stations located within the Bowl were removed from statistical analysis as they are strongly influenced by rapid changes.

In general, the wind velocity distribution is well captured by the model. The simulation results show increased wind velocities for the ridges and bumps, and decreased wind velocities on leeward slopes. The wind-sheltered Bowl, the Vorder Latschüel is characterized by very high wind velocities on the ridge and very low wind velocities within the Bowl. The speed-up effects at the ridges, however, are too high. We believe that the overestimation of speed-up effects at pronounced ridges is a result of insufficient geometrical resolution of sharp crests in the model. As shown in Fig. 5, low wind velocities at the steeper parts of the windward side of the Chüpfenflue indicate a strong blocking of the air flow. The flow blocking in lower parts together with the artificial model layer smoothing through the sigma coordinates - crests are always horizontal over at least one grid spacing artificially cause the model to produce a very high speed-up effect at sharp crests. In reality the air immediately above the crest is still in the blocked air mass. This results in a strong overestimation of wind velocities in the model (Fig. 5).

\subsection{Snow deposition patterns caused by the local flow field}

\subsubsection{Snow deposition patterns}

Change in snow depth (dHS) caused by NW storms is shown in Fig. 6. We can distinguish between different sub-areas according to the snow-depth distribution (Fig. 6). The typical snow depth distribution is discussed in detail by Schirmer et al. (2010b) and Schirmer and Lehning (2010). The Bowl is characterized by homogeneous lee-slope loading, with somewhat enhanced snow deposition in narrow channels. The $N W$ slope is dominated by wind erosion (Fig. 6b, c), with one main deposition zone located on a terrain depression. In contrast, the NE slope is a cross-loaded slope, with a very high spatial variability of dHS. On this slope, two huge accumulation zones developed every winter in the lee of two cross-

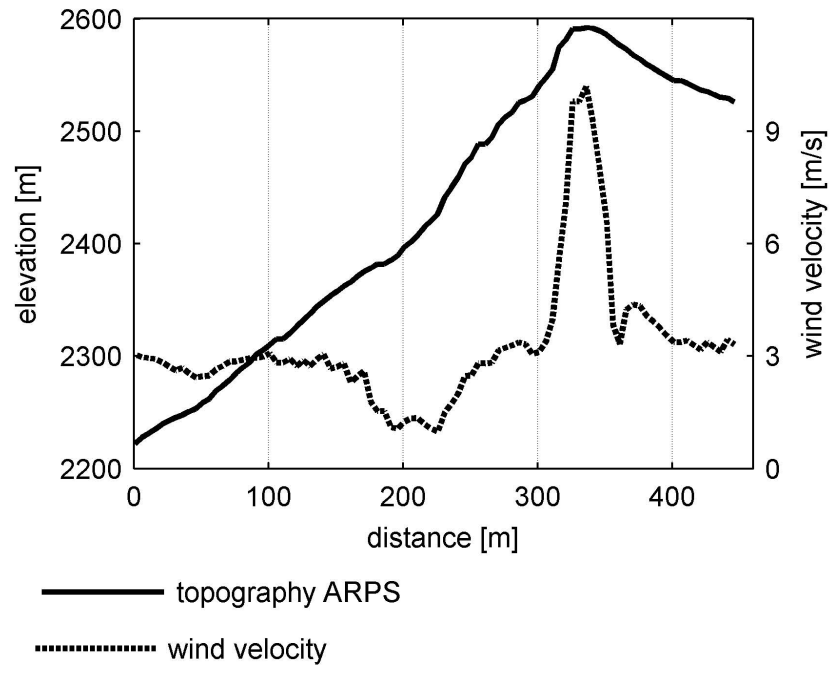

Fig. 5. Transect of the topography and modeled wind velocity crossing the Chüpfenflue in flow direction for NW storms (initialized $\mathrm{vw}=3 \mathrm{~m} \mathrm{~s}^{-1}$ at $2400 \mathrm{~m}$ a.s.1.). Transect is shown in Fig. 1, T4.

slope ridges of bare ground. These accumulation zones were formed during NW storms, when the flow is perpendicular to these ridges, and were interpreted as cornice-like drifts (Fig. 6). The flatter terrain (SW slopes) is strongly characterized by snow filled channels, dells and eroded bumps (Fig. 6).

A qualitative comparison of the measured snow deposition patterns and the simulated dHS after NW storms (Fig. 7) showed that the model is able to capture typical snow deposition patterns (Fig. 6). These are the large accumulation zones (cornice-like drifts) in the lee of the cross-slope ridges on the NE slope, the erosion zones on the NW slope and most of the deposition zones on the $S W$ slopes. The reduced snow deposition on the top of the $N E$ slope is not captured nor is the filling of channels on the flatter terrain ( $S W$ slopes), which we believe is due to a still insufficient horizontal resolution of the small-scale topography. Furthermore the model strongly overestimates the accumulation behind the ridge at the Chüpfenflue, which is due to the overestimation of speedup at this ridge, as discussed above. The highly non-linear response of drifting and blowing snow flux to wind velocity (Doorschot et al., 2004) then leads to a strong overestimation of saltation fluxes and deposition rates in the leeward side of the ridge.

The measurements (Fig. 6) and model results (Fig. 7) showed that the NW storm periods of 2008/2009 with a higher mean snow depth and more frequent NW storms formed more significant deposition patterns than those of 2009/2010. The formation of cornice-like drifts was modeled mainly during snowfall events with wind velocities high enough to initiate snow drift $\left(\mathrm{P}_{0809}, \mathrm{P}_{0809}, \mathrm{P}_{0809}, \mathrm{P} 1_{0910}\right)$. As discussed above, the magnitude of snow deposition and therefore the continuous formation of the cornice-like drifts strongly depend on the forcing wind velocity. In Fig. 8, 

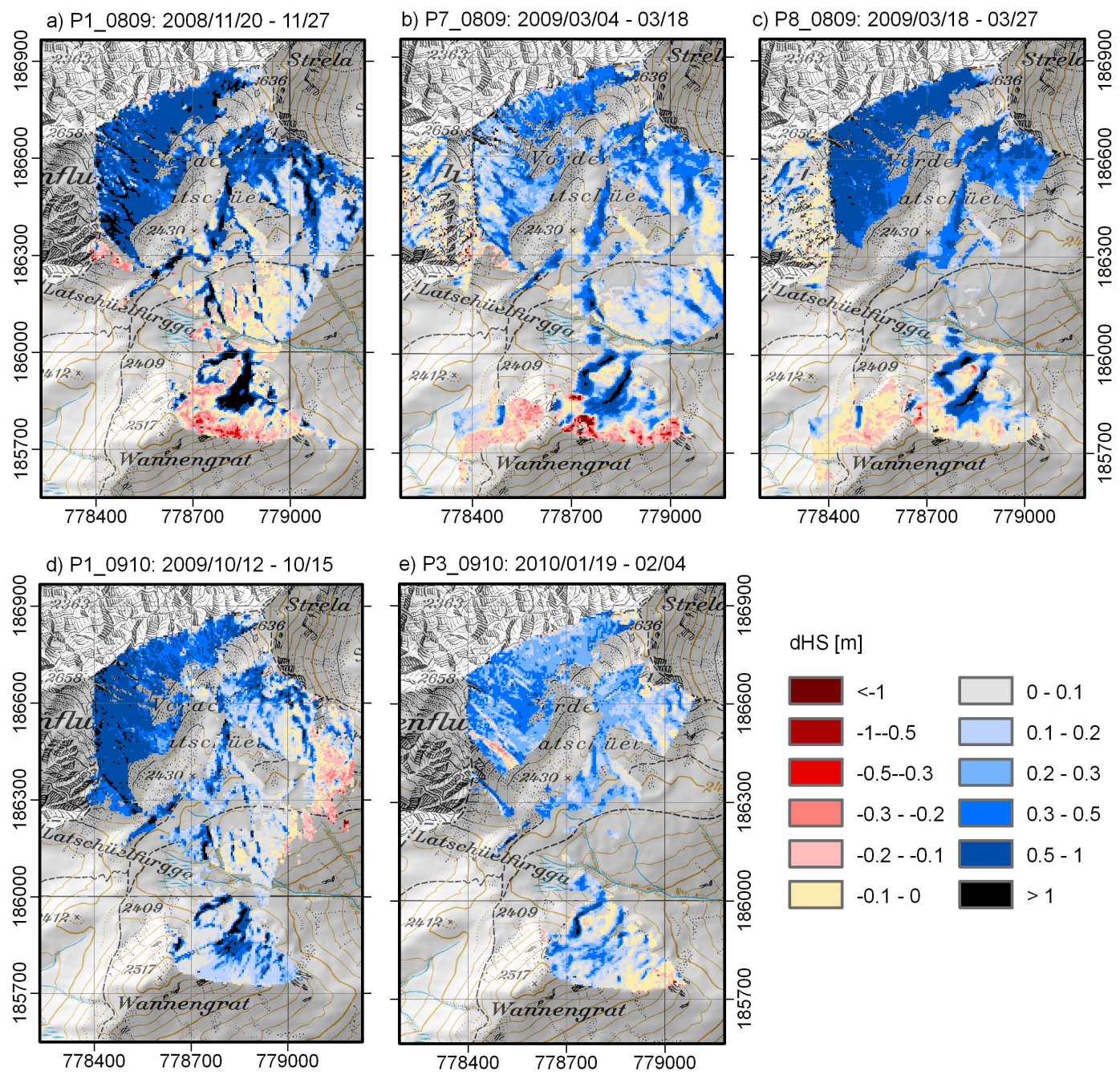

Fig. 6. Measured changes in snow depth (dHS) for the three major snow drift events in 2008/2009 and 2009/2010 during NW storms with precipitation. The $\mathrm{x}$ and $\mathrm{y}$-axes give Swiss coordinates in meters. The horizontal grid resolution of snow-depth measurements were aggregated (mean) to a 5 m grid. (basemap: Pixelkarte PK 25 @ 2009 swisstopo (dv033492)).

dHS at the cornice-like drifts is plotted for snow drift events with high (initialized wind velocity was $7 \mathrm{~m} \mathrm{~s}^{-1}$ ) and moderate (initialized wind velocity was $4 \mathrm{~m} \mathrm{~s}^{-1}$ ) wind velocities. A very large increase in absolute snow deposition, as well as an increase of variance in dHS with wind velocity is clearly visible. This non-linear response is an indication of the dominance of redistribution versus preferential deposition of precipitation, as discussed below.

\subsubsection{Influence of the surface modification on snow-transport processes}

The changes in snow depth for the whole model domain are shown in Fig. 9a for $\mathrm{P}_{0809}$ simulated over bare ground $\left(D_{E M}\right)$. Due to the significant contribution of NW storms to the final snow depth distribution at the time of peak accumulation, we compare modeled dHS to measured HS at the time of peak accumulation 2008/2009 (9 April 2009) (Fig. 9c), obtained from the airborne laser scan. Many of the observed and modeled deposition patterns are similar. In Fig. 9 some of these patterns are shown with circles. It should be noted that a huge avalanche occurred in the Bowl in March 2009, which resulted in different snow deposition patterns in the outrun zone, as well as less snow within the Bowl. The avalanche cannot be captured by the model.

Different modeled deposition patterns were obtained when the same period $\mathrm{P}_{0809}$ was simulated over snow-covered terrain $\left(\mathrm{DEM}_{\mathrm{s}}\right)$ (Fig. 9b). The variability of dHS is lower for simulation runs performed over snow-covered terrain. This is consistent with the observations of Schirmer et al. (2010b), who showed that the variance of dHS due to NW storms tends to decrease during the winter. The modification of the terrain surface due to the snow cover may have a major effect on the local wind field, and thus on the snow distribution after 

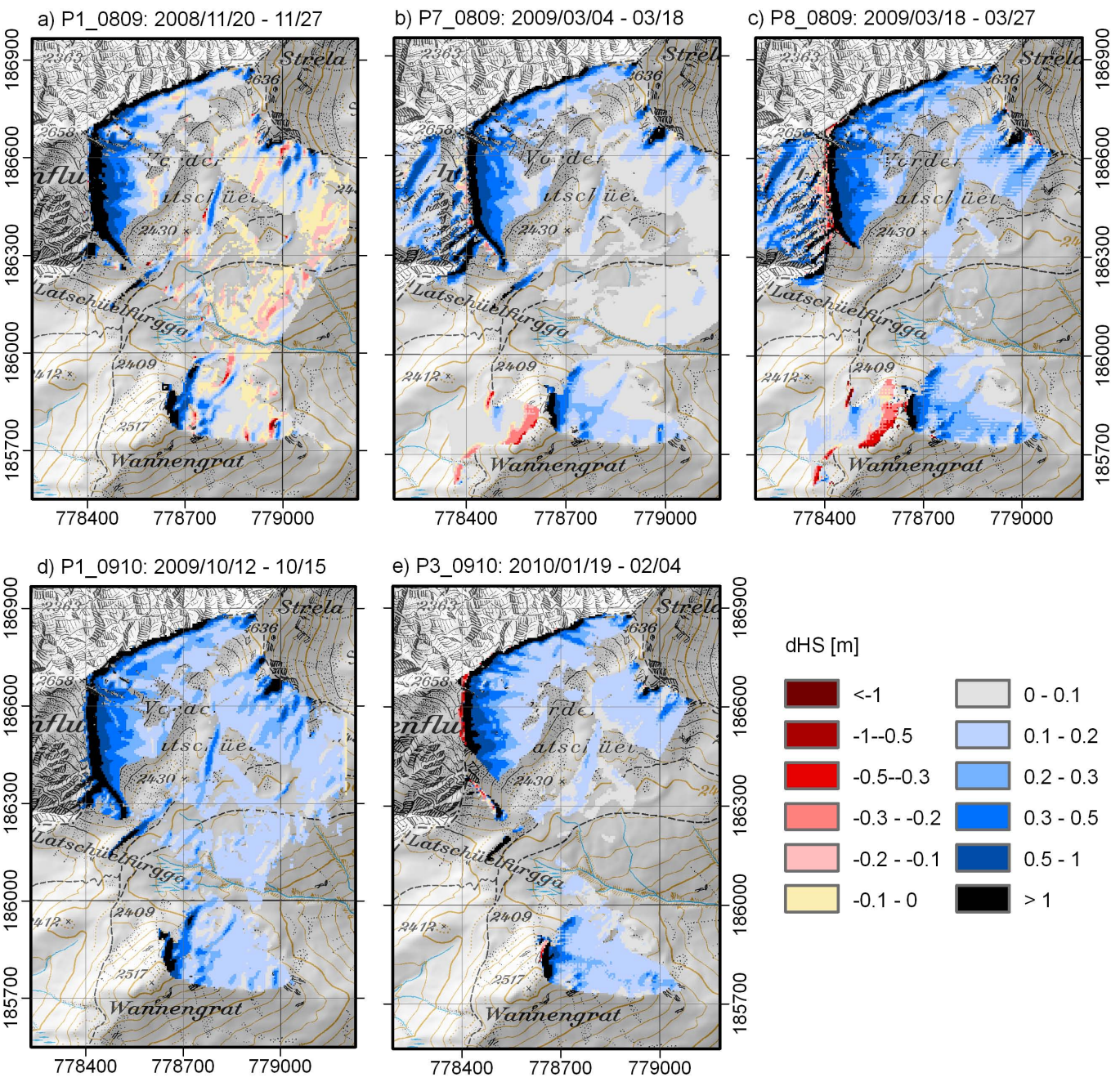

Fig. 7. Modeled changes in snow depth (dHS) for the three major snow-drift events in 2008/2009 and 2009/2010 for north-west wind. The $x$ and y-axes give Swiss coordinates in meters. Only data for grid points covered by measurements are shown. The horizontal grid resolution is 5 m. (basemap: Pixelkarte PK 25 (C2009 swisstopo (dv033492)).

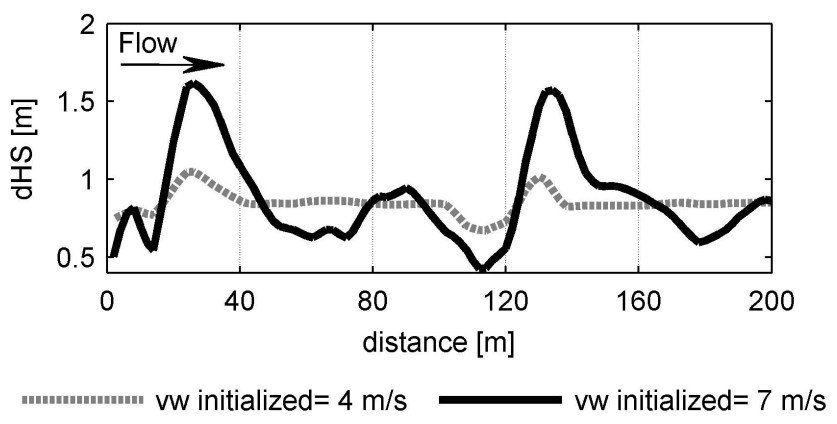

Fig. 8. Transect of modeled dHS crossing the two cross-slope ridges in flow direction, caused by high (initialized $\mathrm{vw}=7 \mathrm{~m} \mathrm{~s}^{-1}$ ) and moderate (initialized $\mathrm{vw}=4 \mathrm{~m} \mathrm{~s}^{-1}$ ) wind velocities. The transect is indicated in Fig. 1, T1. the NW storms. The results from flow-field simulations using the different topographies (not shown) demonstrate a significant influence of the effect of the snow-covered terrain on the flow field. The wind velocity distribution simulated with the $\mathrm{DEM}_{\mathrm{s}}$ (not shown) also became less variable because of the filling of the terrain depressions. On the contrary, on a very local scale wind velocities can become also higher on enhanced snow deposition zones, for example on developed cornices. Consequently, the modeled snow depth changes tend to become smooth towards the end of the accumulation season, especially in the flatter areas, which are dominated by smaller-scale surface structures (Fig. 9b). However, the dominant deposition zones (e.g. cornice-like drifts), as well as the ridge-scale deposition features within the Bowl, were still modeled. 


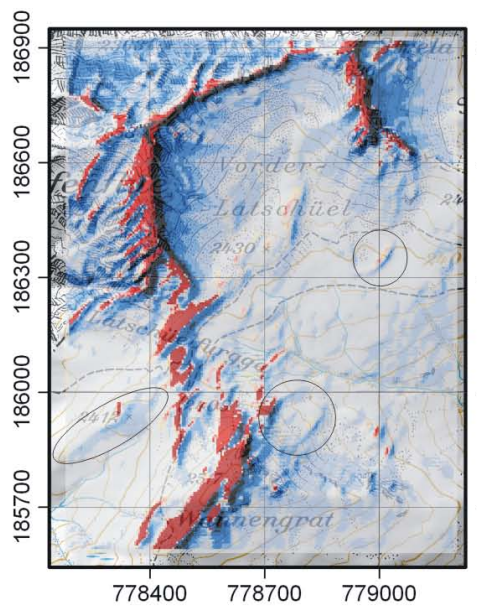

a) dHS, $P 7_{0809} \mathrm{DEM}_{\mathrm{b}}$

$\mathrm{dHS}$ [m]

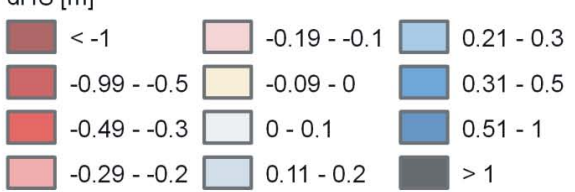

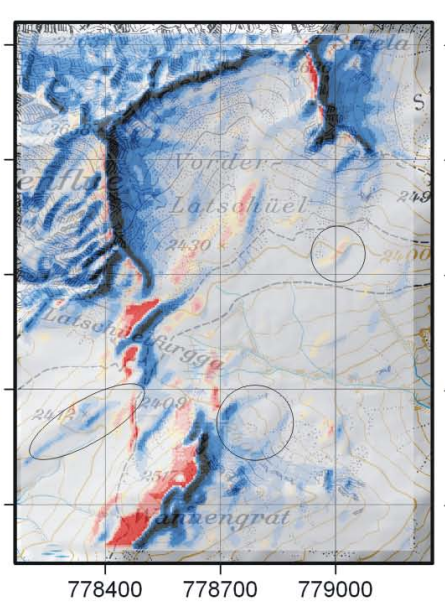

b) dHS, $P 7_{0809} D E M_{s}$

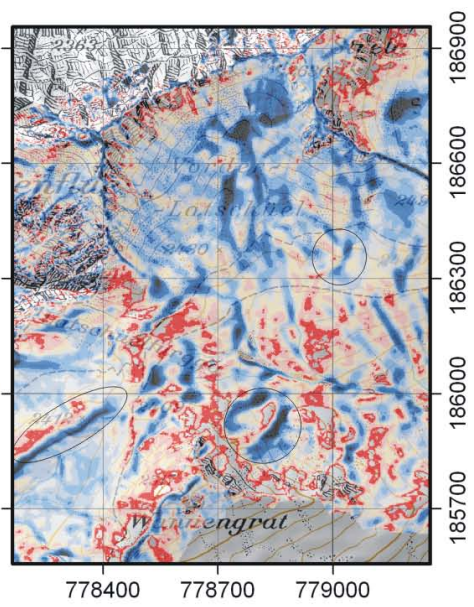

c) HS, 9 April 2009

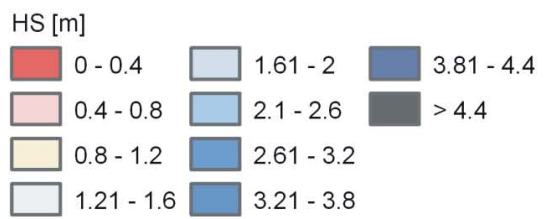

Fig. 9. Modeled changes in snow depth (dHS) for $\mathrm{P}_{0809}$ over bare ground $\left(\mathrm{DEM}_{\mathrm{b}}\right)(\mathbf{a})$ and over snow-covered terrain $(\mathrm{DEM})(\mathbf{b})$ for the whole model domain. Measured snow depths at time of peak accumulation 2008/09 (9 April 2009) with airborne laser scans with a horizontal resolution of $1 \mathrm{~m} \mathrm{(c).} \mathrm{Circles} \mathrm{indicate} \mathrm{consistent} \mathrm{deposition} \mathrm{patterns.} \mathrm{The} \mathrm{x}$ and $\mathrm{y}$-axes give Swiss coordinates in meters. Horizontal grid resolution is 5 m. (basemap: Pixelkarte PK 25 @2009 swisstopo (dv033492)).

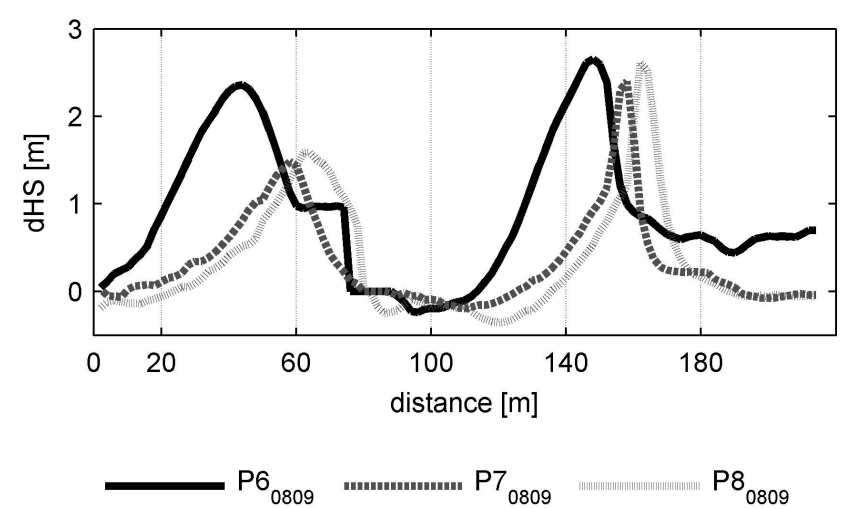

Fig. 10. Transect of measured dHS for periods 6,7 and 8 . Transect T1 is shown in Fig. 1, lowest transect. Transect crosses the cornicelike drifts in flow direction, from northwest to southwest.

We examined the temporal development of the cross-slope cornices and its dependence on the surface modification in more detail. In Fig. 10 the temporal evolution of snow depth on the cornice-like drifts for the accumulation period 2008/09 is shown along a transect line (indicated in Fig. 1). What is clearly visible is that the two cornice-like drifts grew consistently in the course of the accumulation period and the crowns moved in the flow direction. However, the first cornice-like drift grew less than the second. We attribute the different growth dynamics of the two drifts to the fact that snow-deposition processes continuously modified the topography. After the first snowfall of the year, the surface was very rough and then became smooth in the course of the accumulation season. The slope on the leeward side of the first ridge was strongly decreased by snow deposition (Fig. 11a), while the leeward slope of the second drift even slightly increased. The reaction of the flow field and resulting modeled changes in snow depth to the surface modification is analyzed in Fig. 11. The wind field over bare ground showed increased wind velocities on both ridges and decreased wind velocities on the leeward slopes, which resulted in strong gradients of wind velocity over over both ridges. Over snowcovered terrain, the speed-up effects of the wind became less pronounced (Fig. 11b) on the first ridge. The wind simulation on the second ridge also changed to less speed-up, but a high gradient in wind velocity was maintained. The snow-drift processes continued to be active on the second ridge, whereas the snow-redistribution processes acting on the first drift became weaker with time (Fig. 11c). For both drifts, the peak of deposition (i.e. the crown) was shifted about $30 \mathrm{~m}$ in the flow direction. In summary, the snowdrift simulations showed that the snow depth distribution is very sensitive to modifications of the wind due to the local topography, while the topography is consistently modified by snow-transport processes itself. This indicates that the 
a)
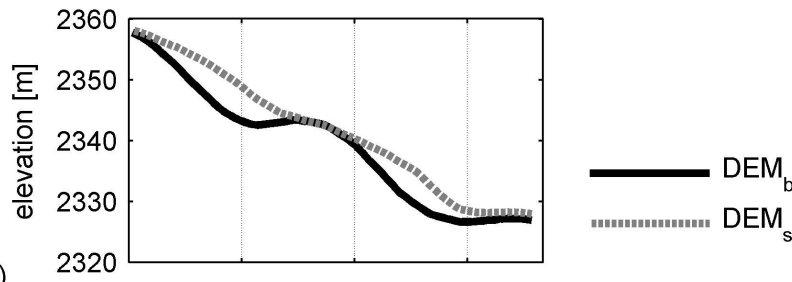

b)

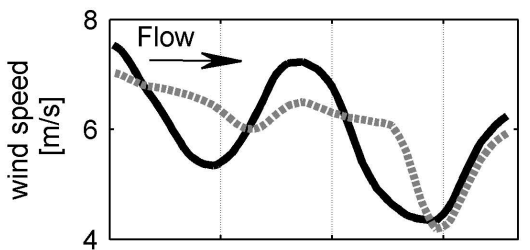

Model input:

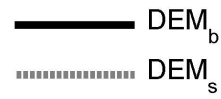

c)

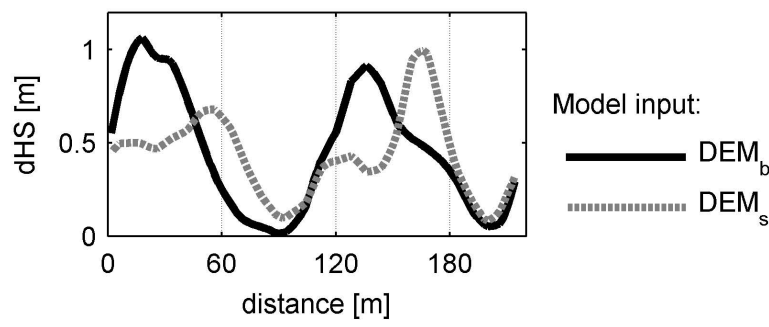

Fig. 11. Transects of bare-ground topography $\left(\mathrm{DEM}_{\mathrm{b}}\right)$ and snowcovered topography $\left(\mathrm{DEM}_{\mathrm{S}}\right)(\mathbf{a})$, modeled three-dimensional wind velocity (b) and modeled dHS (c) for $\mathrm{P} 1_{0809}\left(\mathrm{DEM}_{\mathrm{b}}\right)$ and $\mathrm{P} 8_{0809}$ $\left(D_{\mathrm{S}}\right)$. Transect is shown in Fig. 1, T1. Transect crosses the cornice-like drifts in flow direction, from northwest to southwest.

mechanisms of snow-transport processes shaping the mountain snow-cover are strongly self-regulating.

\subsubsection{Wind-induced snow-transport processes driving the snow deposition in different sub-areas}

In this subsection we want to discuss the dominance of the different processes that drive snow transport, namely saltation, suspension and preferential deposition of precipitation, in different sub-areas within the Wannengrat area. To describe how these processes affect the spatial variability of snow depths in the sub-areas (the Bowl, the NE slope and the $S W$ slopes, Fig. 1), we used the mean $(\mu)$ and the standard deviation $(\sigma)$, for the measured dHS, modeled snow depth change due to preferential deposition of precipitation $\left(\mathrm{dHS}_{\text {prec }}\right)$ and modeled snow depth change caused by the whole range of snow-transport processes $\left(\mathrm{dHS}_{\text {all }}\right)$.

In Fig. 12, $\sigma$ of dHS are given for the whole area for the three drift events in 2008/09 and the model results are compared with the measurements. The simulation results showed a similar trend with a decreasing variance of $\mathrm{dHS}_{\text {all }}$ and $\mathrm{dHS}_{\text {prec }}$ during the winter, associated with the effect of the changing topography on the local wind field (see Sect. 3.2.2). The mean and the standard deviation of dHS for the sub-areas are given in Fig. 13. Measurements showed that the snow

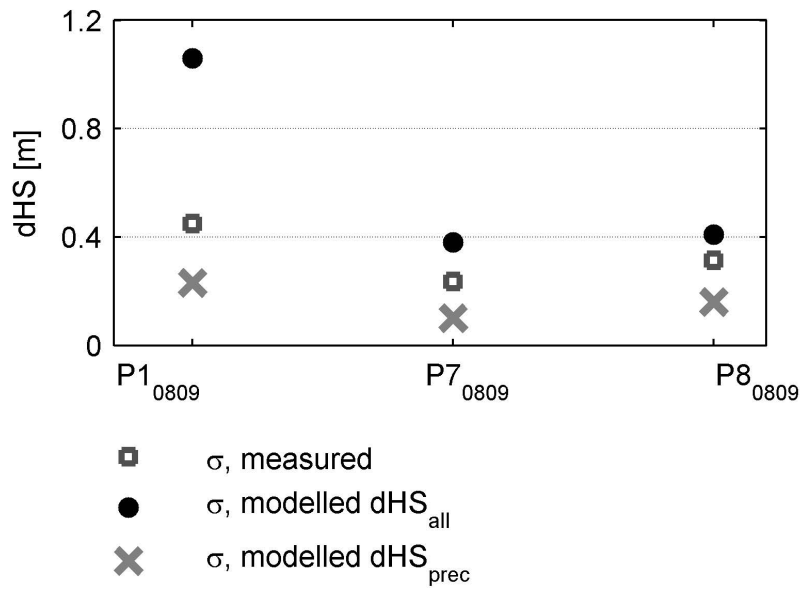

Fig. 12. Standard deviation of measured and modeled changes in snow depth (scanned area). Simulations were run with either all wind-induced snow-transport processes $\left(\mathrm{dHS}_{\mathrm{all}}\right)$ or with preferential deposition of precipitation $\left(\mathrm{dHS}_{\mathrm{prec}}\right)$ only.

depth change of the Bowl was characterized by the highest $\mu$, but the lowest $\sigma$ (Fig. 13a, b). In contrast, for the $N E$ slope $\mu$ was low, but the spatial variability $(\sigma)$ of the snow depth change was the highest. The modeled $\mathrm{dHS}_{\text {all }}$ results in overestimates of $\mu$ (Fig. 13c) and $\sigma$ (Fig. 13d) for the Bowl. This is consistent with the overestimation of the wind velocity, as discussed above, and could be explained by the development of unrealistically large cornices on the ridge of the Chüpfenflue which primarily arise from saltation processes. We therefore introduced a fourth sub-area, the Inner Bowl. If we analyze the Inner Bowl separately, the variance of $\mathrm{dHS}_{\text {all }}$ becomes very low. Similar to the measurements, the highest $\sigma$ (Fig. 13d) and the lowest $\mu$ (Fig. 13c) were calculated for the NE slope.

The simulations of the preferential deposition of precipitation suggested a strong decrease in the total variance (Fig. 13f). For the sub-areas, the modeled $\mathrm{dHS}_{\text {prec }}$ captured the spatial variability very well for the Inner Bowl (Fig. 13b, f), but not for the $N E$ slope. Therefore the preferential deposition of precipitation appeared to be the dominant snowtransport mechanism, causing the low spatial variability of dHS within the Inner Bowl after NW storms (Fig. 13b). In contrast, the high variability of dHS on the NE slope after NW storms (Fig. 13b) could mainly be explained by pure snow drift, i.e. snow redistribution, (Fig. 13c, d), which led to the formation of the cornice-like drifts.

The relative importance of these transport processes in different areas is related to the local wind field as a function of the local topography. In Fig. 14, the modeled $\mathrm{dHS}_{\text {prec }}$ for $\mathrm{P}_{0809}$ (a), the spatial distribution of the three-dimensional wind velocity (b) and the surface-normal wind velocity (c) are shown for one wind field (initialized wind velocity was $5 \mathrm{~m} \mathrm{~s}^{-1}$ ). The flow field simulations (Figs. 4b, 14b) showed that, during synoptically controlled NW flow, the Bowl was 

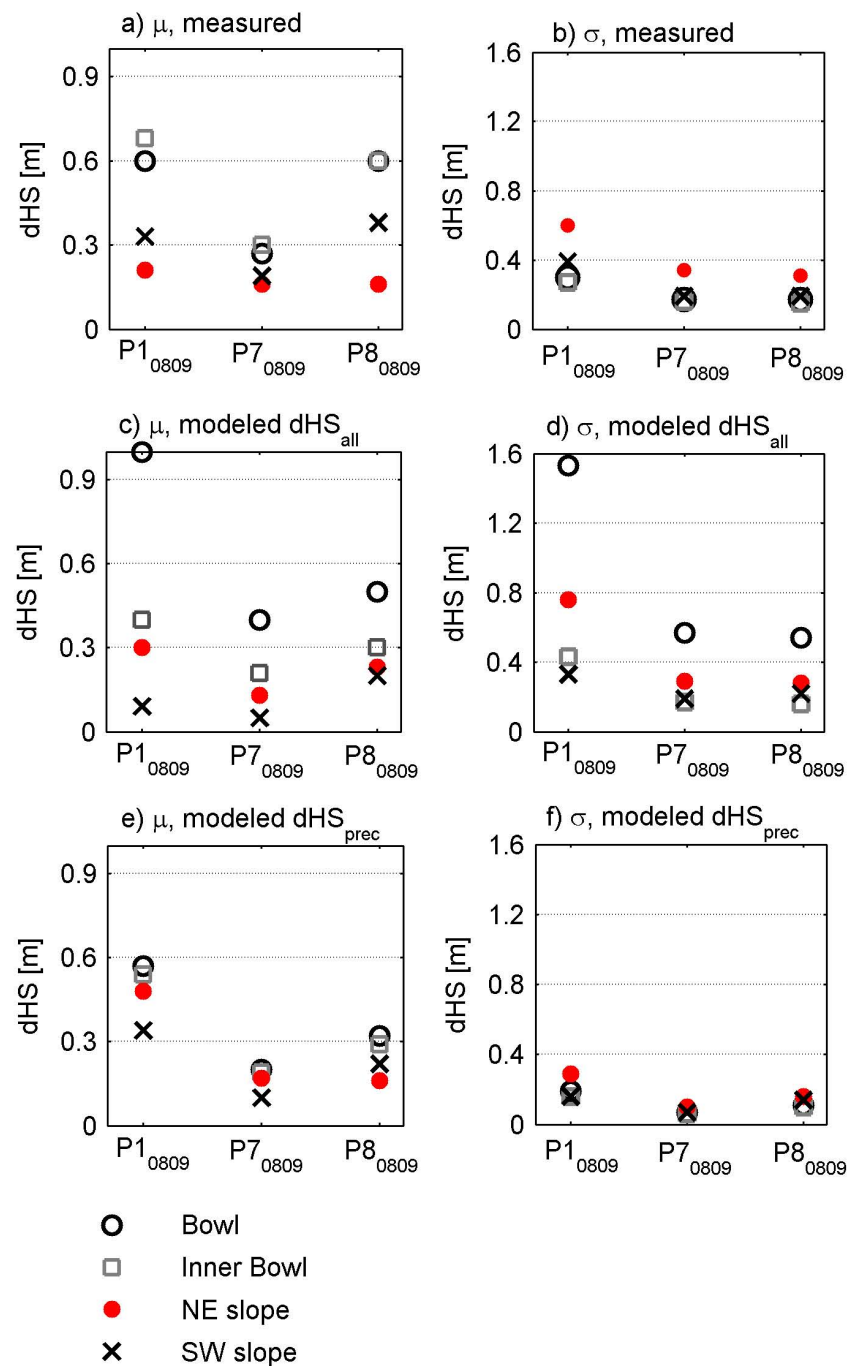

Fig. 13. Mean values (a, c, e) and standard deviation (b, d, f) for measured and modeled dHS for four sub-areas. Modeled dHS were derived from simulations where all wind-induced snow-transport processes $\left(\mathrm{dHS}_{\text {all }}\right)$ were calculated $(\mathbf{c}, \mathbf{d})$, and where only the preferential deposition of precipitation $\left(\mathrm{dHS}_{\mathrm{prec}}\right)$ was simulated $(\mathbf{e}, \mathbf{f})$.

characterized by a high wind velocity gradient on the leeward side of the ridge, which was partly produced by the overestimated speed-up as discussed above. In the Inner Bowl, modeled wind velocities were very low with a very homogeneous distribution of wind velocity (Fig. 14b). The surface-normal wind velocities (Fig. 14c) are highly dependent on the curvature of the small-scale topography. The negative surfacenormal wind velocities at the channels and the eastern part of the Bowl indicate downdraft zones (Fig. 14c). Zones of decreased wind velocities and downdrafts experience stronger preferential deposition of precipitation due to higher deposition velocities of snow. Therefore preferential deposition of precipitation is the dominant snow deposition mechanism in the Bowl (Fig. 13e, 14a). This leads to a more homogeneous lee-slope loading (Lehning et al., 2008) and corresponds with the low variance in snow depth changes observed in the Bowl (Fig. 13b, f). For the $N W$ slope, the numerical analysis suggests that the flow around the Wannengrat pyramid and the associated local speed-up caused an enhanced flow (Fig. 14b) on the NE slope. The positive surface-normal wind velocities (Fig. 14c) indicate strong updrafts on the $N E$ slope. This led to high wind velocities on the windward sides and decreased wind velocities on the leeward sides of the cross-slope ridges. This flow field resulted in pronounced erosion on the windward sides and enhanced deposition on the leeward sides of the cross-slope ridges. Thus, a high spatial variability of the wind field (Fig. 13b) caused considerable redistribution of snow, resulting in a high variance of dHS on the NE slope with a low mean snow depth (Fig. 13b, d) and the formation of huge drifts. The simulation results suggest that these cornice-like drifts, especially the formation of the crowns, were simulated mainly due to snow-redistribution processes (e.g. Fig. 13d).

The strong relationship between the local flow field and the snow depth changes could be confirmed in a correlation analysis for the transects crossing the $N E$ slopes (Fig. 1). In Table 2 the correlation coefficients between the modeled wind field and the measured dHS, as well as for the modeled $\mathrm{dHS}_{\text {all }}$ and the measured dHS are given. All the correlation values were calculated for the three transects crossing the cornice-like drifts in the flow direction (Fig. 1) and for the drift periods $\mathrm{P}_{0809}$ and $\mathrm{P} 8_{0809}$. High positive correlations between the modeled and the measured dHS suggest that the cornice-like drifts were well-captured by the model, especially at the end of the accumulation period. The correlation coefficients for $\mathrm{P}_{0809}$ were lower because the cornicelike drift on the first ridge was simulated too close to the ridge. Furthermore there were high negative correlation coefficients between the three-dimensional wind velocity and the measured dHS for $\mathrm{P}_{0809}$ and $\mathrm{P} 8_{0809}$. This is in accord with the strong correlation between low wind velocities behind the ridges and increased deposition of snow in these areas, while the increased wind velocity due to speed-up effects resulted in more erosion on the windward sides of the crossslope ridges. Even higher negative correlation coefficients were found for the vertical wind velocity, which reflects the strong correlation between downdraft zones (negative vertical wind velocity) and increased deposition of snow. These correlations confirm earlier results on a larger scale (Dadic et al., 2010a) and encourage the development and use of simple parameterization schemes (Dadic et al., 2010b).

\section{Conclusions}

Results from flow and snow-transport modeling help to explain individual snow-transport processes during NW storms. This study drew on the findings of Schirmer et al. (2010b), who showed that the final snow distribution at the time of 

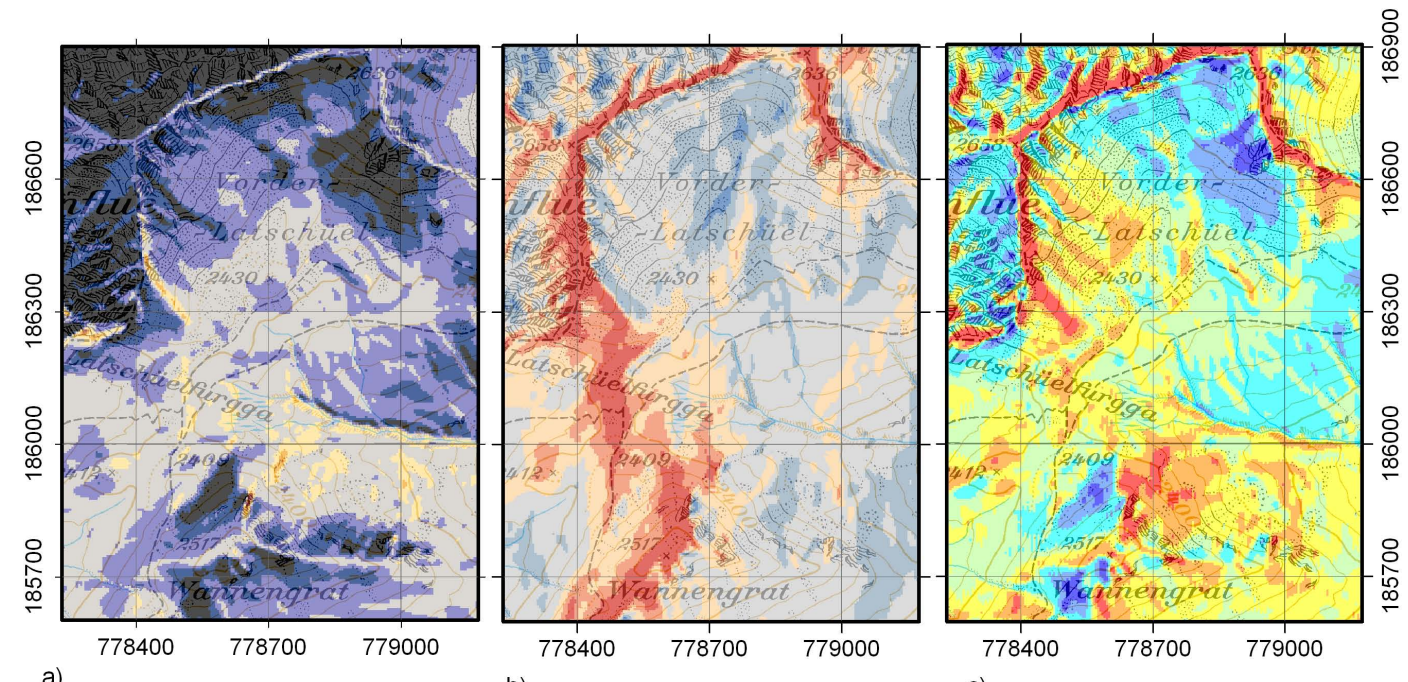

b)
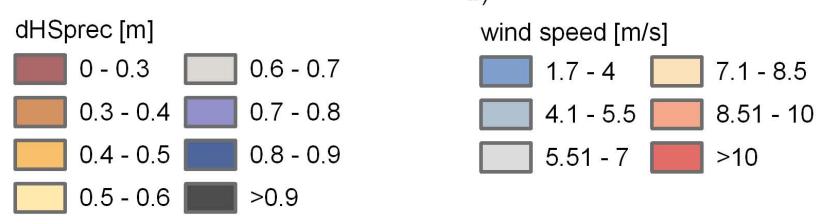

c)

surface-normal wind velocity $[\mathrm{m} / \mathrm{s}]$

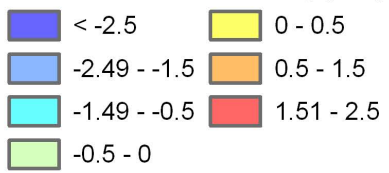

Fig. 14. Changes in snow depth $\left(\mathrm{dHS}_{\mathrm{prec}}\right)$ due to preferential deposition of snow for $\mathrm{P} 1_{0809}(\mathbf{a})$, wind velocity (b) and surface-normal wind velocity (c). The $\mathrm{x}$ and y-axes give Swiss coordinates in meters. (basemap: Pixelkarte PK 25 @2009 swisstopo (dv033492)).

Table 2. Pearson's linear correlation coefficient of measured snow depth change (dHS) against modeled dHS, wind velocity and vertical wind velocity

\begin{tabular}{lrrr|rrr}
\hline & \multicolumn{3}{c|}{$\mathrm{P1}_{0809}$} & \multicolumn{3}{c}{$\mathrm{P}_{0809}$} \\
\cline { 2 - 7 } Transects & \multicolumn{1}{c}{$\mathrm{T} 1$} & \multicolumn{1}{c|}{$\mathrm{T} 2$} & \multicolumn{1}{c}{$\mathrm{T} 3$} & \multicolumn{1}{c}{$\mathrm{T} 1$} & \multicolumn{1}{c}{$\mathrm{T} 2$} & \multicolumn{1}{c}{$\mathrm{T} 3$} \\
\hline dHS & 0.25 & 0.56 & 0.27 & 0.64 & 0.59 & 0.75 \\
wind velocity & -0.44 & -0.56 & -0.65 & -0.37 & -0.60 & -0.51 \\
vertical wind velocity & -0.70 & -0.53 & -0.62 & -0.69 & -0.45 & -0.70 \\
\hline
\end{tabular}

peak accumulation is mainly shaped by "master" storms (i.e. NW storms) and that these storms created persistent accumulation patterns. We have been able to demonstrate that most snow-deposition patterns found at the time of peak accumulation can be explained and modeled with the help of a few mean flow fields calculated by ARPS. Our numerical analysis shows that these storms produce very characteristic flow patterns, with small-scale flow features such as local speed-up effects developing over sub-slope terrain structures (e.g. cross-slope ridges) and ridge-scale flow features, such as flow blocking or wind separation developing as a result of larger-scale terrain features. These flow features on different scales appear to be very important for different snow-transport processes. The drift simulations suggest that the snow distribution of the NE slope is governed mainly by saltation/suspension processes, while that in the Bowl is mainly influenced by preferential deposition of precipitation.
In particular, two huge cross-slope cornice-like drifts on the $N E$ slope developed only when the prevailing wind direction was NW and were formed mainly through snow redistribution processes (saltation-driven).

Changing topography was also found to have a significant effect on the flow field and the final snow distribution. The modification of the topography has been found to be the main reason for the decrease in variance of observed snow depths caused by NW storms during the winter. Over snow-covered terrain, smaller-scale terrain features were not present anymore and therefore only the larger-scale terrain features continued to shape flow field modification and the associated snow deposition. In contrast, very small-scale and largerscale terrain features had a considerable impact on the flow field over bare ground resulting in a very variable snow depth distribution and saltation becoming more important. The dynamics of the drift formation strongly depend on the feedback between snow-deposition processes, the changing topography and the local wind field, especially for the temporal development of the cornice-like drifts.

Schirmer et al. (2010b) tried to reproduce the spatial patterns of snow-depth distribution using a simple terrain analysis (Winstral et al., 2002), and were in fact able to produce the main spatial patterns. They failed, however, to reproduce the magnitude of the observed variability. In contrast, the physical approach we used captured the effect of a nonlinear response of snow-transport processes to wind velocity variations and allowed the individual processes involved to 
be separated. The main advantage of our study is that our description of snow depth variability is process-oriented. We are able to show that special flow conditions always lead to similar deposition patterns, which should provide a basis for simpler parameterizations of snow deposition caused by drift and the preferential deposition of precipitation such as already demonstrated by Dadic et al. (2010b).

The main purpose of this investigation was to use physical modeling to explain observed deposition patterns as shaped by individual storms during the accumulation period. To capture the total snow mass balance the calculation of sublimation of blowing snow will be necessary. Current work on the implementation of sublimation into the snow-transport model of Alpine3D shows that on a local scale snow depths are considerably overestimated if sublimation is neglected (Groot Zwaaftink and Lehning, 2010). As a next step, we plan to investigate how the local flow field affects the scaling characteristics of the snow depths caused by NW storms. In particular, we are interested if we can find coherent scaling parameters between the spatial distribution of snow depths and wind velocities. We note that we only work with mean flow fields and do not explicitly consider the highly turbulent flow nor the mostly intermittent snow transport. A logical further step would therefore be to make use of the advanced performance of Large-Eddy Simulations (Chamecki et al., 2008) to investigate the limits of our equilibrium descriptions. We further note that we have not simulated a full time development of the snow cover and in particular for the purpose of slope stability estimations based on weak layer modeling (Schirmer et al., 2010a). This would be a mandatory requirement, which we want to tackle in our continuing effort.

Acknowledgements. The wind simulations were made using the Advanced Regional Prediction System (ARPS) developed by the Center for Analysis and Prediction of Storms (CAPS), University of Oklahoma. Part of the work was funded by the Swiss National Science Foundation and the European Community 7th Framework programme STREP project HYDROSYS (Grant 224416, DG INFSO). We are grateful to our colleagues who helped during the field campaigns and acquiring measurement data, especially Vanessa Wirz, Nicholas Dawes, Christoph Marty and Luca Egli. We thank Sylvia Dingwall for language editing and the two anonymous reviewers who helped to improve the paper considerably.

Edited by: S. Dery

\section{References}

Bellaire, S. and Schweizer, J.: Measuring spatial variations of weak layer and slab properties with regard to snow slope stability, Cold Reg. Sci. Technol., doi:10.1016/j.coldregions.2010.08.013, in press, 2010.

Bernhardt, M., Liston, G. E., Strasser, U., Zängl, G., and Schulz, K.: High resolution modelling of snow transport in complex terrain using downscaled MM5 wind fields, The Cryosphere, 4, 99-113, doi:10.5194/tc-4-99-2010, 2010.

Chamecki, M., Meneveau, C., and Parlange, M. B.: A hybrid spectral/finite-volume algorithm for large eddy simulation of scalars in the atmospheric boundary layer, Bound.-Lay. Meteorol., 128(3), 473-484, 2008.

Clifton, A. and Lehning, M.: Improvement and validation of a snow saltation model using wind tunnel measurements, Earth Surf. Proc. Land., 33, 2156-2173, 2008.

Dadic, R., Mott, R., Lehning, M., and Burlando, P.: Wind influence on snow depth distribution and accumulation over glaciers, J. Geophys. Res., 115, F01012, doi:10.1029/2009JF001261, 2010a.

Dadic, R., Mott, R., Lehning, M., and Burlando, P.: Parameterization for Wind-Induced Preferential Deposition of Snow, Hydrol. Process., 24, 1994-2006, 2010 b.

Doorschot, J., Lehning, M., and Vrouwe, A.: Field measurements of snow drift threshold and mass fluxes, and related model simulations, Bound.-Lay. Meteorol., 113(3), 347-368, 2004.

Essery, R.: Spatial statistics of wind flow and blowing snow fluxes over complex terrain, Bound.-Lay. Meteorol., 100, 131-147, 2001.

Fang, X. and Pomeroy, J. W.: Modelling blowing snow redistribution to Prairie wetlands, Hydrol. Process., 23, 2557-2569, doi:10.1002/hyp.7348, 2009.

Gauer, P.: Numerical modeling of blowing and drifting snow in Alpine terrain, J. Glaciol., 47(156), 97-110, 2001.

Groot Zwaaftink, C. D. and Lehning, M.: Sublimation of drifting snow in an Alpine catchment, Extended abstracts, 14th Conference on Mountain Meteorology, Lake Tahoe Vicinity, USA, Amer. Meteor. Soc., Paper 8.3., 2010.

Grünewald, T., Schirmer, M., Mott, R., and Lehning, M.: Spatial and temporal variability of snow depth and ablation rates in a small mountain catchment, The Cryosphere, 4, 215-225, doi:10.5194/tc-4-215-2010, 2010.

Helbig, N., Löwe, H., and Lehning, M: Radiosity approach for the shortwave surface radiation balance in complex terrain, J. Atmos. Sci., 66, 2900-2912, 2009.

Helbig, N., Lehning, M, Löwe, H., and Mayer, B: Explicit validation of a surface shortwave radiation energy model over snow covered complex terrain, J. Geophys. Res., 115, D18113, doi:10.1029/2010JD013970, 2010.

Lehning, M., Doorschot, J., and Bartelt, P.: A snow drift index based on SNOWPACK model calculations, Cold Reg. Sci. Technol., 31, 382-386, 2000.

Lehning, M., Löwe, H., Ryser, M., and Raderschall, N.: Inhomogeneous precipitation distribution and snow transport in steep terrain, Water Resour. Res., 44, W09425, doi:10.1029/2007WR006544, 2008.

Lehning, M. and Fierz, C.: Assessment of snow transport in avalanche terrain, Cold Reg. Sci. Technol., 51, 240-252, doi:10.1016/j.coldregions.2007.05.012, 2008.

Lewis, H., Mobbs, S. D., and Lehning, M.: Observations of crossridge flows over steep terrain, Q. J. Roy. Meteor. Soc., 134, 801816, 2008.

Liston, G. E. and Elder, K.: A meteorological distribution system for high-resolution terrestrial modeling (MicroMet), J. Hydrometeorol., 7(2), 217-234, 2006.

Liston, G. E., Haehnel, R. B., Sturm, M., Hiemstra, C. A., Bere- 
zovskaya, S., and Tabler, R. D.: Instruments and methods simulating complex snow distributions in windy environments using SnowTran-3D, J. Glaciol., 53(181), 241-256. 2007.

Luce, C. H., Tarboton, D. G., and Cooley, K. R.: The influence of the spatial distribution of snow on basin-averaged snowmelt, Hydrol. Process., 12(10-11), 1671-1683, 1998.

Male, D. H.: The seasonal snowcover, in: Dynamics of Snow and Ice Masses, edited by: Colbeck, S. G., Academic Press, 305-395, 1980.

Mellor, M.: Blowing Snow, CRREL, Monogr. III-A3c, 1965.

Mott, R. and Lehning, M.: Meteorological modeling of very-high resolution wind fields and snow deposition for mountains, J. Hydrometeorol., 11, 934-949, 2010.

Mott, R., Faure, F., Lehning, M., Löwe, H., Hynek, B., Michlmayr, G., Prokop, A., and Schöner, W.: Simulation of seasonal snow-cover distribution for glacierized sites on Sonnblick, Austria, with the Alpine3D model, Ann. Glaciol., 49, 155-160, 2008.

Pomeroy, J. W. and Gray, D. M.: Saltation of snow, Water Resour. Res., 26(7), 1583-1594, 1990.

Pomeroy, J. W., Marsh, P., and Gray, D. M.: Application of a distributed blowing snow model to the Arctic, Hydrol. Process., 11(11), 1451-1464, 1997.

Prokop, A.: Assessing the applicability of terrestrial laser scanning for spatial snow depth measurements, Cold Reg. Sci. Technol., 54(3), 155-163, 2008.

Prokop, A., Schirmer, M., Rub, M., Lehning, M., and Stocker, M.: A comparison of measurement methods: terrestrial laser scanning, tachymetry and snow probing, for the determination of spatial snow depth distribution on slopes, Ann. Glaciol., 49, 210216, 2008.

Purves, R., Barton, J., Mackaness, W., and Sugden, D.: The development of a rule-based spatial model of wind transport and deposition of snow, Ann. Glaciol., 26, 197-202, 1998.

Raderschall, N., Lehning, M., and Schär, M.: Fine-scale modeling of the boundary layer wind field over steep topography, Water Resour. Res., 44, W09425, doi:10.1029/2007WR006544, 2008.

Schaffhauser, A., Adams, M., Fromm, R., Jörg, P., Luzi, G., Noferini, L., and Sailer, R.: Remote sensing based retrieval of snow-cover properties, Cold Reg. Sci. Technol., 54(3), 164-175, 2008.
Schirmer, M. and Lehning, M.: Persistence in intra-annual snow depth distribution, Part 2: Fractal analysis of snow depth development, Water Resour. Res., submitted, 2010.

Schirmer, M., Lehning, M., and Schweizer, J.: Statistical evaluation of local to regional snowpack stability using simulated snowcover data, Cold Reg. Sci. Technol., 64(2), 110-118, 2010 a.

Schirmer, M., Wirz, V., Clifton, A., and Lehning, M.: Persistence in intra-annual snow depth distribution, Part 1: Measurements and topographic control, Water Resour. Res., submitted, 2010b.

Schmidt, R. A.: Transport rate of drifting snow and the mean wind speed profile, Bound.-Lay. Meteorol., 34(3), 213-241, 1986.

Schweizer, J., Jamieson, B., and Schneebeli, M..: Snow avalanche formation, Rev. Geophys., 41(4), 1016-1041, 2003.

Skaloud, J., Vallet, J., Keller, K., Veyssiere, G., and Kölbl, O.: An eye for landscapes - rapid 15 aerial mapping with handheld sensors, GPS World, 17, 26-32, 2006.

Stössel, F., Manes, C., Guala, M., Fierz, C., and Lehning, M.: Micrometeorological and morphological observations of surface hoar dynamics on a mountain snow-cover, Water Resour. Res., 46, W04511, doi:10.1029/2009WR008198, 2010.

Swiss Experiment: www.swiss-experiment.ch, access: October 2010.

Tabler, R. D.: Predicting profiles of snowdrifts in topographic catchments, P. West. Snow Conf., 43, 87-89, 1975.

Uematsu, T., Nakata, K., Takeuchi, K., Arisawa, Y., and Kaneda, Y.: Three-dimensional numerical simulation of snowdrift, Cold Reg. Sci. Technol., 20(1), 65-73, 1991.

Winstral, A. and Marks, D.: Simulating wind fields and snow redistribution using terrain-based parameters to model snow accumulation and melt over semi-arid mountain catchment, Hydrol. Process., 16(18), 3583-3603, 2002.

Winstral, A., Elder K., and Davis, R. E.: Spatial snow modeling of wind-redistributed snow using terrain-based parameters, J. Hydrometeorol., 3(5), 524-538, 2002.

Xue, M., Droegemeier, K. K., Wong, V., Shapiro, A., and Brewster, K.: The Advanced Regional Prediction System (ARPS) - A multi-scale non-hydrostatic atmospheric simulation model, Part 2: Model physics and applications, Meteorol. Atmos. Phys., 76, 143-165, 2004. 